This is an unedited manuscript published in the

Journal of Career Assessment, 16(3).

Please note that the published version has undergone minor additional editing in style and content.

Please cite as

Hirschi, A., \& Läge, D. (2008). Using accuracy of self-estimated interest-type as a sign of career choice readiness in career assessment of secondary students. Journal of Career Assessment, 16(3), 310-325. doi: 10.1177/1069072708317372

\title{
Using Accuracy of Self-Estimated Interest-Type as a Sign of Career Choice Readiness in Career Assessment of Secondary Students
}

\author{
Andreas Hirschi ${ }^{1, *} \&$ Damian Läge ${ }^{1}$ \\ ${ }^{1}$ University of Zurich, Department of Psychology \\ ${ }^{*}$ Corresponding author \\ Andreas Hirschi, \\ Damian Läge \\ Leuphana Universität Lüneburg, Institute for \\ Universität Zürich, Psychologisches Institut, \\ Strategic HR Management Research and \\ Angewandte Kognitionspsychologie \\ Binzmühlestr. 14 \\ Development (SMARD), Wilschenbrucher Weg \\ CH - 8050 Zürich \\ 84, D-21335 Lüneburg, Germany, Phone \\ Switzerland \\ +4941316777 776, Fax +4941316777935, \\ Telephone: +41446357440 \\ Email: andreas.hirschi@leuphana.de \\ E-Mail: d.laege@psychologie.unizh.ch
}


Accuracy of Self-Estimated Interest Type and Career Choice Readiness 2

Using Accuracy of Self-Estimated Interest-Type as a Sign of Career Choice Readiness in Career Assessment of Secondary Students

A frequent applied method in career assessment to elicit clients' self-concepts is asking them to predict their interest assessment results. Accuracy in estimating one's interesttype is commonly taken as a sign of more self-awareness and career choice readiness. The study evaluated the empirical relation of accuracy of self-estimation to career choice readiness within a sample of 350 Swiss secondary students in seventh grade. Overall, accuracy showed only weak relations to career choice readiness. However, accurately estimating one's first interest-type in a three-letter RIASEC interests-code emerged as a sign of more vocational identity and total career choice readiness. Accuracy also correlated positively with interest profile consistency, differentiation, and congruence to career aspirations. Implications of the results for career counseling and assessment practice are presented.

Keywords: interest assessment, self-estimation, career choice readiness, secondary students, career counseling, RIASEC typology 
Vocational interests have long been one of the dominant research topics in vocational psychology and assessment of vocational interests is common practice in today's career counseling (Watkins, Campbell, \& Nieberding, 1994). Following the emerge of constructivist career theories and qualitative career assessment (cf. McMahon \& Patton, 2002; Savickas, 2005; Young \& Collin, 2004), in the modern view of career assessment the counselor should not just function as an expert who makes a diagnosis and tells the clients their assessment results. Contrary to this "test-and-tell" approach today's view of career assessment argues that the client should play an active part in the assessment process. Assessment results are not only for making an objective expert diagnosis but also for clients to clarify their personal selfconcept. In this line, the personal meaning of the assessment results for the client becomes a major focus in career counseling (McMahon \& Patton, 2002; Savickas, 2005).

One method which is frequently used by practitioners and is recommended in the professional literature to elicit the personal self-concept of a client is to ask clients to predict their own results in the interest inventory (Hansen, 2005; Zytowski, 1999). This subjective picture of the client's interests can then be compared to the test results and the similarities and differences can be further elaborated in the counseling session.

Another use of such self-estimates are that they can give a clue about the client's self-awareness of his or her interests. Self-awareness is commonly assumed to be an important aspect of career choice readiness (e.g., Crites, 1978). The most popular and well researched model of vocational interests is Holland's (1997) RIASEC typology of vocational interest and personality types. When using interest inventories based on this theory in career counseling and assessment, it is frequently recommended that they can not only be used to identify the client's major areas of interest. By considering the secondary constructs of Holland's theory, the interest profile can also give information about the client's state of career development, "personal career theory", and state of career choice readiness (e.g., Holland, 1997; Reardon \& Lenz, 1999). Although the results have not always been consistent to theory, a large number of studies has been conducted whether interest profile differentiation, congruence of inventoried interests to career aspirations, coherence of career aspirations, or consistency in dominant interest types show meaningful relations to measures of career choice readiness and career maturity (see Holland, 1997, for a review).

Almost neglected in the professional literature, however, is the possibility that selfestimates of one's own interest profile can also be used as an indicator of career choice readiness in career assessment. In contrast to the many studies who explored meaning and predictive use of expressed interests in terms of career aspirations (e.g., Gottfredson, 2002a; 
Rojewski, 2005; Silvia, 2001), almost no research has been conducted regarding expressed interests in terms of self-estimates of one's own interest type. A notable exception is the study by Healy and Mourton (1983), who reported very promising results for the use of selfestimates in career counseling as an indication of career choice readiness. Indeed, in their study accuracy in estimating one's interest profile emerged to be a better measure for career choice readiness than the more frequently used secondary constructs of differentiation, consistency, or congruence.

Career choice readiness can be described as the readiness of a person to engage in career decision-making and successfully master the career decision-making process (Super, 1990). The older concept of career maturity has been criticized on theoretical grounds in the past years, for example, because it did not sufficiently incorporate current aspects of motivational psychology, lacked to incorporate the influence of the environment, or is based on an old-fashioned concept of endogenous maturity (e.g., Phillips \& Blustein, 1994; Savickas, 2001; Vondracek \& Reitzle, 1998). Modern concepts of the career decision-making process also stress that becoming decided and certain about one's future occupation though a systematic career decision-making process might not be as important as older models of career maturity and career decision-making have proposed. However, a more updated and inclusive understanding of career maturity in terms of career choice readiness still remains a useful concept until today (Savickas, 2001). Research over the past decades showed repeatedly that a high amount of career choice readiness is substantial for successful career decision-making. For example, adolescents with higher readiness are more successful in mastering the transition from school to work or further education (e.g., Bergmann, 1993; Hirschi \& Werlen Lutz, submitted; Patton, Creed, \& Muller, 2002; Seifert, 1993), are less affected by dysfunctional stress in career decision-making (Seifert, 1983) and have a higher degree of social adjustment (Savickas, Briddick, \& Watkins, 2002).

Despite the promising results of linking accuracy of self-estimation to the degree of career choice readiness and their potential value for the practice of career assessment, Healy and Mourton's study has not been replicated or extended by subsequent research. For example, the results should be replicated with other groups of clients since their study used 138 community college students from only three majors, thus representing a very specific and biased sample in regard of their educational level and interest-types. The study did also not report findings regarding possible gender differences and did not include theoretically relevant measures like career aspirations or degree of vocational identity. 


\section{Research Questions and Hypotheses}

In career counseling and assessment practice, the counseling process is mostly constrained by time limitations. Besides the assessment of interests, counselors might also want to assess and discuss other constructs such as personality, values or cognitive ability. Hence, when presenting the clients his or her interest results counselors might be in need of a simple and short description of the basic interest types. Existing assessment devices also provide such descriptions which might be used for that purpose (Holland, 1994; Jörin, Stoll, Bergmann, \& Eder, 2004). Following the study of Healy and Mourton (1983), the goal of the present study is to evaluate whether secondary students are capable of correctly estimating their interest type according to such a short description and whether the accuracy in estimating one's interest profile is positively related to career choice readiness.

Contrary to college students, secondary students are clearly in a different state of career development. For them, the task of career decision-making is a very new topic and they just begin to evaluate career options based on their personal interests (cf. Gottfredson, 2002b). Vocational interests become a major focus for general and vocational identity development at that age (Skorikov \& Vondracek, 1998). Thus, vocational interests start to form a central component in the self-concept of secondary students. However, since age is a critical factor for cognitive and social development for adolescents it might also be that older students are better capable to correctly estimate their interest type.

Hypothesis A1) Based on the study conducted by Healy and Mourton (1983) we assume that the ability of estimating one's interest profile is positively connected to a clear vocational identity and more total career choice readiness.

Hypothesis A2) Students with more differentiated interest profiles are assumed to be better able to predict their interest profile.

Hypothesis A3) Although Healy and Mourton's study could not find such relationships we further assume that accuracy of self-estimates shows positive relations to coherence of career aspirations and congruence of interest profile to career aspirations, since all of these measures can be seen as a sign of more self-awareness according to Holland's (1997) theory.

Hypothesis A4) Healy and Mourton assumed that consistency in one's interest profile is a sign of more career choice readiness and self-awareness but could not conclusively find this relation. In the latest statement of his theory Holland (1997) writes that consistency is primarily related to stability in aspirations and successive jobs of a person. The direct 
connection to career choice readiness and self-awareness is no more assumed. We therefore postulate that consistency shows no significant relation to accuracy of self-estimation.

We also wanted to evaluate whether gender, scholastic aptitude or age have an influence on accuracy of self-estimation.

Hypothesis B1) Different studies found that female students show more knowledge about the world of work and are more advanced in their career development than their sameage male classmates (e.g., Creed \& Patton, 2003; Creed, Prideaux, \& Patton, 2005). We therefore assume that female students also show better self-estimates of their interest type.

Hypothesis B2) Estimating one's interest type is a cognitive task which requires processing of complex information about oneself and an interest-type description. Healy and Mourton (1983) found that GPA correlated positively with accuracy. We therefore assume that students with more scholastic aptitude have better self-estimates.

Hypothesis B3) Because of the cognitive and social development that takes place during adolescence we assume that older students are better able to correctly estimate their interest type.

\section{Method}

\section{Subjects}

Participants were 350 secondary students at the end of grade 7 (49.4 percent female). The students came from 20 different school classes and 5 different school districts of the southern part of the Canton St. Gallen, Switzerland. The students ranged from 12 to 16 years of age $(M=14.07, S D=.697) .1$ student was 12 years old, 62 students (17.7 percent) 13 years old, 209 students (59.7 percent) 14 years old, 19 students (19.7 percent) 15 years old, and 9 (2.6 percent) 16 years old. This rather large span of age differences within only one grade is due to the fact that students can start schooling earlier or later according to their cognitive and social development in pre-school. Also, some students have to repeat certain grades if their school marks are not sufficient to progress to the next grade.

128 (36.6 percent) of the subjects visited a school-type with basic academic requirements, the others a school-type with advanced requirements. Students in classes with advanced requirements generally show more scholastic aptitude and also have more career options to choose from, including general high-school which can lead to college education. 
Students from classes with basic academic requirements have to choose a vocational education after grade nine which normally will not lead to a later college education.

\section{Measures}

\section{Career choice readiness.}

Five measures were used for career choice readiness:

Vocational Identity was measured with a German adaptation of the Vocational Identity Scale (Holland, Daiger, \& Power, 1980) from Jörin et al. (2004). The ten-item scale asks students to indicate on a 5-point Likert scale how much certain statements resemble their personal vocational situation (e. g. "I'm not sure yet which occupations I could perform successfully"). Hirschi and Werlen Lutz (submitted) provide positive evidence for the content and criterion validity of this scale. The mean score in our sample on this scale was 34.36 $(S D=7.57)$. The internal stability (Cronbach) was .85 .

Career Decidedness was measured with the respective scale from the German adaptation from Seifert and Stangl (1986) of the Career Maturity Inventory (Crites, 1973). The scale consists of 12 items (e. g. "I don't know exactly what to do in order to choose the right occupation"). Responses are indicated on a four-point scale ranging from "not agree at all" to "totally agree". Several studies by the authors of the scale and others present evidence for content and criterion validity (Bergmann, 1993; Hirschi \& Werlen Lutz, submitted; Seifert, 1983, 1993; Seifert, Bergmann, \& Eder, 1987). The internal reliability (Cronbach) for this scale in the present study was .86. The mean score was $34.47(S D=6.54)$.

Career Planning was measured using the respective scale from the German adaptation from Seifert and Eder (1985) of the Career Development Inventory (Super, Thompson, Lindeman, Jordaan, \& Myers, 1981). The 22-item scale consists of three parts. Part one (9 items) asks about how much one has thought about different activities concerning career choice. Part two (5 items) is about how much time one has invested in thinking about career relevant questions. Part three ( 8 items) asks how much one knows about preferred occupations. Answers are given on a 5-point scale. Different studies have shown the content and criterion validity of this scale (Hirschi \& Werlen Lutz, submitted; Seifert, 1993; Seifert et al., 1987; Seifert \& Eder, 1985, 1991). The internal stability in our sample was .90, the mean score was $69.17(S D=13.57)$.

Career Exploration was also measured with the respective scale from the German adaptation of the Career Development Inventory (Seifert \& Eder, 1985; Super et al., 1981). 
The scale is divided into two parts. Part one (13 items) asks students to indicate, whether they would consult different sources of information for their career development (e. g. my father, my teacher, job-shadowing). Answers can be given on a 5-point scale ranging from "in no case" to "definitely". Part two (13 items) asks how much useful information they have already obtained from these same sources. Answers are indicated on a 5-point scale with end points of "none" to "very much". As for the Career Planning Scale several studies confirmed the content and criterion validity of this scale (Hirschi \& Werlen Lutz, submitted; Seifert, 1993; Seifert et al., 1987; Seifert \& Eder, 1985, 1991). The internal stability in the present study was .85 , the mean score was $85.68(S D=14.54)$.

Total Career Choice Readiness. In order to get a measure for the total career choice readiness of a student we calculated a total career choice readiness scale based on the four scales presented above. First, the four-point item scale of the career decidedness scale was linearly transformed into a 5-point item scale to make it comparable to the other scales. Next, we calculated the mean-score for each scale by dividing the sum-score by the number of items of the scale. Finally, we summed up the mean-scores and divided the value by four. Thus, each of the four scales adds one fourth to the total career choice readiness scale which ranks from 1 to 5 . The mean score of the scale was $3.34(S D=0.51)$. The reliability (Cronbach) of this scale was .93 .

\section{Career Aspirations.}

Each student was asked to list his or her current career aspirations. The first three aspirations were each assigned a three-letter Holland RIASEC code according to the register of vocational codes provided by Jörin et al. (2003). The students named between 0 and 11 concrete career aspirations $(M=2.79, S D=1.64)$.

\section{Vocational interests.}

Each student completed the AIST-R Allgemeiner Interessen-Struktur-Test [General Interest-Structure-Inventory] (Bergmann \& Eder, 2005) which is a very common interest inventory based on Holland's theory in German speaking countries. The authors of the inventory provide extensive evidence for content and criterion validity. Each interest-type is assessed with 10 items describing a typical activity of that type (e. g. "learn a foreign language", "work on a construction-side") and students are asked to indicate on a five-point scale how much interest they have in this particular activity, ranking from "This interests me a lot; I like to do that very much" to "This interests me not at all; I don't like to do that". Contrary to the SDS (Holland, 1994) the items for a specific type are presented in alternate 
order and the test user is not aware of which item belongs to which type. The raw values were transformed to standard values $(M=100 ; S D=10)$ with the tables provided by Bergmann and Eder (2005). The students in our study showed the following distribution of vocational interests: Realistic $M=100.41, S D=9.68$; Investigative $M=99.54, S D=9.20$; Artistic $M=100.09, S D=10.35$; Social $M=99.33, S D=12.03$; Enterprising $M=99.63, S D=9.11$; Conventional $M=100.45, S D=10.27$. The mean internal stability (Cronbach) of the scales in the present sample was $.866(S D=.03)$ and ranged from .851 (Investigative) to .921 (Social). The three types with the highest standard values were taken as the three-letter interest type of a student. Based on this we built a scale ranking from 0 to 3 for each RIASEC-type. 1 to 3 points were assigned to a type according to its position in the three letter code with 3 points given for the first position. Types that were not among the first three were assigned zero points. If the profile was tied for the first three types (which was the case for 27 percent of the subjects) the higher point-score of the possible combination was used for a specific interest type (e.g., for the tied profile $\mathrm{R} / \mathrm{A} \mathrm{C}$ both $\mathrm{R}$ and $\mathrm{A}$ were assigned three points and $\mathrm{C}$ one point).

\section{Accuracy of self-estimates.}

We measured self-estimates of Holland-types for the first three types because the three letter-code is most commonly used in counseling and in classification of occupations. Taking account of time restrictions in actual assessment practice, each student was presented a simple and short written description of each RIASEC type. The descriptions ranged between 52 and 77 words and included typical interests, skills, and values of the types according to the description provided by Holland (1997) and Jörin et al. (2004). The students had to name the three types which best resemble their personality and interests and write them down in the corresponding order. Based on this three-letter self-estimation code we calculated four different values for accuracy of self-estimation.

First, we calculated a scale ranking from 0 to 3 for each RIASE-type according to its position in the self-estimated three-letter code. The same was done for the inventoried interest profile as explained above. Accuracy was then calculated as the sum of the absolute differences between the self-estimation and the interest inventory scores for each type plus a constant of one (Accuracy $=\sum_{6}^{1} \mid$ estimated type-inventoried type $\left.\mid+1\right)$. Thus, lower points resemble better self-estimates. We name this measure Difference-index. The mean score in our study was $4.82(S D=2.51)$. 
For the other three measures of accuracy we used different indices of congruence. The indices to measure congruence are commonly used in research to measure the similarity between two different three-letter RIASEC-codes. However, the literature on congruence indices is far from conclusive. While some studies report remarkable differences in results depending on the index used to measure congruence (e.g., Assouline \& Meir, 1987; Camp \& Chartrand, 1992) others report that they correlate to a very high degree and can be used interchangeably (e.g., Young, Tokar, \& Subich, 1998). Because of this ambiguity we decided to measure accuracy of self-estimates with different indices which are all based on different mathematical models. When the first three types of the interest profile were tied, we calculated congruence for each possible first three-letter code and took the mean value as the final value of accuracy for that student.

The Holland-index (Holland, 1997) is calculated by comparing only the first letter of the three-letter codes and assigning a value of 1 to 4 for similarity according to their respective position on the RIASEC hexagon. This leads to a normal distribution of values where low (1 point) and high (4 points) similarity is rather seldom while medium similarity (2 and 3 points) is more common. Although this index provides a rather rough value of similarity its advantage lies in its simplicity and practical relevance for counselling. The students in our study achieved a mean similarity between self-estimates and their interest profile of 3.4 $(S D=.88)$ for this index.

The Zener-Schnuelle-index (Z-S-index; Zener \& Schnuelle, 1976), considers all three letters of an interest-code. The index assigns a value of 0 to 6 for similarity based on their overall probability of occurrence, with 6 representing the most unlikely and highest degree of similarity. In the present study the student's mean value for the Z-S-index was 3.53 $(S D=1.61)$.

The $C$-index (Brown \& Gore, 1994) is currently cited as the best available index of congruence (cf. Eggerth \& Andrew, 2006) because it takes into account all three letters, is based on their similarity according to the RIASEC hexagon and has an underlying normal distribution for its values, which range from 0 to 18 . The mean score accuracy of selfestimates calculated with this index was $12.80(S D=3.89)$ in the present study.

The three congruence measures for accuracy showed a mean correlation of .699 $(S D=0.126)$ in our study with the highest correlation between the C-index and the Hollandindex (.810) and the lowest between the Z-S-Index and the Holland-index (.562). The mean correlation of the Difference-index to the three congruence indices was $.659(S D=0.168)$. 
Measures of the secondary constructs.

Coherence of vocational aspirations was measured by comparing the first letters of the first three career aspirations of a student for their similarity (cf. Reardon \& Lenz, 1999). When all three belong to the same type coherence is high (3 points) when two belong to the same type it is medium ( 2 points) and if all three belong to a different type it is low (1 point). Because this measure requires that a students does at least name three concrete career aspirations it could only be calculated for 172 students (49.1 percent of all subjects). The mean score of coherence in the present study was $2.05(S D=.720)$.

Differentiation of interests was measured by calculating the standard deviation of the standard codes from the interest profile. These raw values where then transformed to standard values using the tables from Bergmann and Eder (2005). The mean value of differentiation in our sample was $102.35(S D=10.51)$.

Congruence was measured using the same three indices as described for the measure of accuracy of self-estimation: the Holland-index, the Z-S-index, and the C-index. The three measures correlated with $\mathrm{r}=.717(S D=0.083)$ in our sample. The highest correlation was between the C-index and the Z-S-index (.807), the lowest between the Holland-index and the Z-S-index (.643). Using these measures we calculated the congruence between the interest profile and each of the first three career aspirations and took the mean value as the final score of congruence for a student. Again, when interest profiles were tied for the first three types we calculated congruence for all possible combinations and took the mean value as the final score of congruence for a certain aspiration. For our subjects the mean values of congruence were $2.92(S D=0.88)$ for the Holland-index, $2.72(S D=1.38)$ for the Z-S-index, and 11.44 $(S D=2.94)$ for the C-index.

Consistency was measured by comparing the first two interest-codes in the interest profile according to their position in the RIASEC hexagon and assigning a value of 1 to 3 (see Holland, 1997). When the two types are next to each other in the Hexagon (e.g., Realistic and Investigative) the consistency is high (3 points), when they are opposite (e.g., Realistic and Social) it is low (1 point) and the other combinations (e.g., Realistic and Artistic) show medium consistency ( 2 points). The mean value of consistency in our sample was 2.52 $(S D=0.636)$. 


\section{Procedure}

All students were handed a questionnaire tapping career choice readiness, vocational interests, self-estimation of interest-type, vocational aspirations, and asking them to indicate gender and school-type. Half of the students first completed the self-estimation, then named their career aspirations, completed the measures for career choice readiness, and finally completed the interest inventory. The other half of the students first completed the interest inventory and last the self-estimation. All students completed the questionnaire during an ordinary school-lesson in their classrooms under the supervision of their classroom teachers.

\section{Results}

Accuracy of Self-Estimates

\section{Preliminary analysis.}

We first evaluated how accurate the students could estimate their inventoried interest type. In order to get unequivocal values we only considered those students who had a clear three-letter code in their interest-profile, thus showing no tied values for the first three types ( $\mathrm{N}=255 ; 54.9 \%$ female; $34.5 \%$ basic academic requirements). Parametric t-test showed that this group shows no significant differences in any of the career choice readiness measures compared to students with tied interest profiles. However, Chi-Square tests showed that students with basic academic requirements $\left(\chi^{2}(1)=4.572, p<.05\right)$ and female students $\left(\chi^{2}(1)=23.60, p<.001\right)$ are overrepresented compared to the group with tied profiles.

Of the 255 students with no tied profiles 169 (66.3\%) were able to predict their first letter-code correctly (the probability of estimating one's first code correctly by chance is 16.7 percent, $\left.\chi^{2}(1)=451.83\right) .90$ students $(35.3 \%)$ estimated their first two codes correctly (chance probability 2.5 percent, $\left.\chi^{2}(1)=819.69\right)$ and 38 students $(14.9 \%)$ had a correct self-estimation for the whole three letter code (chance probability 0.8 percent, $\chi^{2}(1)=617.34$ ). As the ChiSquare Tests showed, all frequencies are significantly different from the chance probability $($ all $\mathrm{p}<.001)$.

As another measure for the level of accuracy we calculated the absolute difference between the self-estimated rank and the inventoried rank of an interest type for the students with no tied ranks in the interest inventory $(\mathrm{N}=255$; Realistic $M=0.47, S D=0.83$; Investigative $M=0.64, S D=0.85$; Artistic $M=0.53, S D=0.80$; Social $M=0.37, S D=0.68$; Enterprising $M=0.83, S D=0.86$; Conventional $M=0.69, S D=0.85)$. We also calculated 
Pearson correlations between the self-estimated and the inventoried interest type for all students. $(\mathrm{N}=350$; Realistic $\mathrm{r}=.688$; Investigative $\mathrm{r}=.493$; Artistic $\mathrm{r}=.636$; Social $\mathrm{r}=.770$; Enterprising $\mathrm{r}=.268$; Conventional $\mathrm{r}=.488$; each $\mathrm{p}<.001$ ). As both measures show, the different types are estimated with different accuracy. For example, the Social type is estimated with the best accuracy while students estimate the Enterprising type much less accurately.

\section{Group differences.}

To test Hypothesis B1) we compared male and female students with parametric ttests on the four measures of accuracy of self-estimation for significant differences. Female students showed a better accuracy of self-estimates on all four measures but only with the Difference-index (female $M=4.40, S D=2.32$ vs. male $M=5.25, S D=2.64, t(348)=-3.19$, $\mathrm{p}<.01$ ) and the Z-S-index (female $M=3.69, S D=1.54$ vs. male $M=3.33, S D=3.69$, $t(352)=2.08, \mathrm{p}<.05)$ the differences are significant. Hypothesis B1) that female students have better self-estimates than male students can therefore be confirmed, although the difference is not very large.

To test Hypothesis B2) that students with more scholastic aptitude have better selfestimates we compared the students from classes with advanced academic requirements to those with only basic requirements by parametric t-tests. Only the Difference-index showed a significant result: students from classes with advanced academic requirements had better selfestimates $(M=4.64, S D=2.56$ vs. $M=5.13, S D=2.42, t(348)=-1.77, \mathrm{p}$ (one-tailed) $<.05)$. No significant differences emerged with any of the three measures of congruence. Hypothesis B2) can therefore only be confirmed with some reservation.

To test Hypothesis B3) that older students would have better self estimates than younger students we compared students of age 13,14, 15 and 16 with univariate analyses of variance (ANOVA) with each of the four accuracy measures as dependent variables for potential differences. The one student with age 12 was excluded for these analyses. As the results show, no significant differences between the age groups emerged with any of the four accuracy measures (Difference-Index: $F(3,13.86)=0.73, \quad \mathrm{p}=.534$; Holland-Index: $F(3,2.61)=1.12, \mathrm{p}=.340 ;$ ZS-Index $F(3,4.98)=0.64, \mathrm{p}=.587$; C-Index: $F(3,36.95)=0.81$, $\mathrm{p}=.489$ ). Hypothesis B3) must therefore be rejected: Age has no systematic relation to accuracy of self-estimation within our subjects. 


\section{Accuracy of Self-Estimation and Career Choice Readiness}

The main Hypothesis A1) was that accuracy of self-estimation (ASE) of one's interest type is a sign of more career choice readiness. To test this hypothesis we calculated Pearson correlations for the measures of ASE with the measures of career choice readiness. To test Hypothesis A2) and A3) that accuracy of self-estimates are positively related to interest differentiation, coherence of career aspirations, and congruence we also calculated the correlations for these measures with ASE (see Table 1).

\section{[Insert Table 1 about here]}

As the results show, ASE showed only one significant correlation to a measure of career choice readiness: accuracy correlates positively with vocational identity when calculated with the Difference-index and the Holland-index. However, accuracy of selfestimates correlates positively with interest differentiation, congruence and (with the Hollandindex and C-index) consistency. No significant correlation was found between ASE and coherence with any of the four measures. Thus, Hypothesis A1) that ASE would be positively connected to career choice readiness could only partially be confirmed for vocational identity but not for total career choice readiness. The positive relation of ASE to interest differentiation (Hypothesis A2) and to congruence was confirmed. However, contrary to our expectation ASE showed not significant relations to coherence, thus only partially confirming Hypothesis A3. The positive correlations found between ASE and consistency was contrary to Hypothesis A4.

As a second test for Hypothesis A1), we compared the students who accurately estimated their first type with students who did not by parametric t-tests for their level of career choice readiness (Table 2). Again, for this analysis we only considered the students with no tied values for the first three codes in their interest profile $(\mathrm{N}=255)$. As the results show, students who estimated their first letter-code correctly also showed a slightly higher vocational identity and more total career choice readiness. The same comparison for students who correctly estimated the first two letters and for students who correctly estimated their whole three-letter code to those who did not, could not reveal any significant differences between the groups. These results mean that Hypothesis A1) is only true for accurate selfestimation of the first interest type but not for the following types. 
[Insert Table 2 about here]

\section{Discussion}

Asking clients to predict their interest inventory results is a frequently applied counseling technique in career assessment. The technique is commonly used to elicit a client's self-concept which can then be compared to the inventory results and the personal meaning of the similarities and differences can be further explored in counseling. The accuracy of the clients self-estimate also is proposed to be a sign of self-awareness and career choice readiness. Despite its theoretical logic and practical relevance almost no empirical studies have investigated the relation between accuracy of self-estimates and career choice readiness. Our study evaluated whether accuracy in estimating one's personal interest type can really be regarded as a sign of more career choice readiness for secondary students.

Generally, the quality of self-estimation was moderate to high with 66.3 percent of the students correctly estimating their fist interest type. The Social type was estimated with the best accuracy while students had most difficulties in estimating the Enterprising type correctly. To get a clearer picture of this finding we compared the number of students whose first self-estimated interest-type was the Enterprising type to the number of students whose first type was the Enterprising type according to the interest profile. The result shows that significantly more students had a self-estimation as Enterprising than an interest inventory result as Enterprising $\left(\chi^{2}(1)=6.03, p<.05\right)$. Thus, students significantly overestimated themselves in the Enterprising type. An explanation for this finding could be that, contrary to the Realistic and Social interest-types, the Enterprising type is frequent for both male and female students. Thus, a large group can relate to the characteristics and interests of that type. This might be the reason why the Enterprising type is more difficult to estimate and is frequently overestimated.

As our results show, female students were better able to predict their interest-type, although the differences were only minor. This difference is in line with previous research findings that female students have better knowledge of the world of work and are more advanced $\mathrm{n}$ their career development than same-age male classmates (e.g., Creed \& Patton, 2003). We also compared male and female students on their degree of vocational identity and total career choice readiness: The two sexes did not differ significantly in vocational identity and male students even showed more total career choice readiness $(p<.05)$. Thus, we can not assume that female students generally showed more self-awareness. The two groups also 
show no meaningful difference in interest-profile differentiation which could explain this result. Whether our finding is generally valid should thus be confirmed by future research.

Healy and Mourton (1983) found that GPA scores correlate positively with accuracy of self-estimation within their subjects. In our study only a weak effect was found in accuracy between students from classes with advanced academic requirements and those with only basic requirements. Confirming our hypothesis, students with advanced requirements had better self-estimates. To double check this finding we dummy-scaled the two school-types with $1=$ advanced requirements and $0=$ basic requirements. The Spearman correlation showed a weak significant correlation for the Difference-index of accuracy $(r=.107, p<.05)$. Thus, although the difference is rather small, our study confirms the findings of Healy and Mourton that scholastic aptitude is positively related to accuracy of self-estimation.

We also analyzed whether older students are better capable than younger ones to correctly estimate their interest type. This is especially critical since our participants where only in seventh grade. One might thus argue that they are too young to correctly estimate their own basic interests. However, due to the special demands of the Swiss education system, these students are actually expected to soon engage in the career decision-making process. Hence, they are an important group to investigate. Our sample of students provided an optimal condition to analyze whether age is indeed a critical factor for correct self-estimation: All students where in the same grade, regardless of their age differences. Hence, age and grade where not confound variables as is mostly the case in other studies. This is important because in Switzerland formal career choice education starts in grade eight. Thus, better selfestimates of students in higher grades might be due to formal education and not because of their age. Contrary to our hypothesis, however, older students did not show better selfestimates than younger ones. This implies that the ability to correctly estimate one's interest type does not depend on mere age, even for young adolescents. One has to keep in mind, however, that the inter-individual differences in cognitive and social development during adolescence can be huge. Thus, formal age might be a poor indicator of the actual state of development of an individual student during adolescence.

Contrary to our basic assumption, accuracy of self-estimation did not prove to be a valid measure for career choice readiness, with the exception that it showed minor positive relations to vocational identity. Only the correct estimation of one's first interest type proved to be a sign of more career choice readiness. As our analysis revealed, two-third of the students were able to correctly predict their first interest-type. Those who did showed a more developed vocational identity and also more total career choice readiness than the minority 
who failed to accurately predict their basic type. Whether students correctly estimated two or all three of their first three interest-types was, however, no sign of more career choice readiness in comparison to students who could not do so. While generally accuracy of selfestimation showed almost no connection to career choice readiness, it correlated meaningfully to congruence, interest profile differentiation, and interest profile consistency. The positive connection between accuracy of self-estimation and congruence was in line with our assumption, since both can be seen as a sign of more self-awareness. Confirming this argument is the above not reported finding that congruence showed positive correlations to vocational identity $(\mathrm{r}=.154, \mathrm{p}<.01, \mathrm{C}$-index $)$. Contrary to our expectation, coherence of vocational aspirations was not positively related to accuracy of self-estimation. Coherence was also not significantly related to vocational identity $(r=.137, p=0.72)$. Thus, in our study coherence did not prove to be a sign of more self-awareness which might explain the nonsignificant relation to accuracy of self-estimation. Our results that students with more differentiated interests are also better able to estimate their interest-type was expected and confirms the finding by Healy and Mourton (1983).

However, in some important points our results do not match with the findings from Healy and Mourton (1983). In their study accuracy of self-estimation was positively related to career choice readiness but not to congruence and consistency, which is the exact opposite of our results. One might assume that a weak relation of accuracy of self-estimation to career choice readiness within our groups of secondary students could be because estimating one's interest-type is a very complex cognitive task of which older college students are better able than students in early adolescence. Thus, for college students the accuracy scale could have a better validity and stability. Unfortunately, Healy and Mourton do not report detailed data on the degree of accuracy within their sample to test this assumption. Contradicting this argument, however, is our finding that accuracy of self-estimation did show clear and meaningful relations to congruence and differentiation, confirming the basic validity of the self-estimation of our sample. A more persuasive argument for the different finding might be found in the measures applied for career choice readiness. As in our study, Healy and Mourton did not find significant correlations between accuracy of self-estimation and career planning or career exploration. The significant correlations they found were to other aspects of career choice readiness such as ability in career decision-making, knowledge of the world of work and of one's preferred occupations. This means that accuracy of self-estimation is mainly connected to certain abilities and knowledge in career decision-making, such as being clear about one's own interests, skills, and values (vocational identity), having skills in career 
decision-making and knowledge of one's possible options. It shows only negligible relations to a feeling of decidedness or to positive attitudes towards and behaviors in career planning or career exploration.

One possible explanation for the failure to find a significant relation between accuracy of self-estimation and congruence in Healy and Mourton's (1983) study could be the fact that their sample of college students represented only three types of majors, thus showing a restricted variance in preferred occupational areas and thus a restricted variance of congruence. Another point is that they used a rather uncommon measure for congruence. In our study, the subjects represented a very heterogeneous sample of vocational interests and the congruence indices applied are commonly used in today's research and practice. We would therefore assume that our results represent a more valid picture of the true relation between accuracy of self-estimation and congruence.

Also contradicting Healy and Mourton's study is our finding that consistency was positively related to accuracy of self-estimation. Although contrary to our expectation, this finding implies that consistency is indeed a sign of more self-awareness, as proposed by Healy and Mourton. While their study with community college students could not confirm this assumption, our results imply that it might be true for secondary students who are just about to form their vocational identity. Conflicting this argument, however, is our finding that vocational identity and interest consistency showed no significant correlation in our study $(\mathrm{r}=.021)$. Thus, the relation of self-awareness and interest consistency needs further empirical investigation.

\section{Strengths and Limitations of the Study}

One strength of our study is the heterogeneous group of subjects. They represented a broad area of vocational interest and scholastic aptitude. We also used more up to date and sophisticated measures for our calculations than did previous studies. Our approach to calculate accuracy of self-estimation with not only one but four different measures proved to be very useful. Not every measure resulted in the same conclusion and certain relations might have been overlooked if not several measures had been applied.

A weakness of the study is that scholastic aptitude was not directly measured. Although students in different school-types do clearly differ in their average scholastic aptitude, there can be a considerable overlap in actual ability between the two groups. Future studies could evaluate to what degree accuracy of self-estimation is a matter of general intelligence by applying standard intelligence-tests along with tapping self-estimation. 
Another limitation of our study is the fact, that our measures of accuracy strongly dependent on the positive side of self-estimation, as an indication what one $i s$ like. However, sometimes indication what one is not like is more easy and can also be seen as a sign of selfawareness. Following studies could, for example, ask students to name the two types which are most like them and the two types which are least like them. In this way the measure would give equal weight to both positive and negative self-estimation.

Our measure of self-estimation relied on a short and simple written description of typical interests, skills, and values of the six Holland types. Due to existing time restrictions in actual counseling and assessment practice such an approach to elicit a self-estimation might be very practical and frequently applied. However, one might argue that this is insufficient for students in seventh grade to fully comprehend these types which might influence the reliability and validity of our measure. Basically, we believe that our measure proves sufficient convergent validity since the self-estimations are clearly more accurate compared to the applied interest inventory than would be expected by chance and shows significant correlations to the interest inventory. Our measure is also highly objective since all students received the exactly same information about the types. However, we can not provide any direct evidence for its reliability and it might be possible that a more thorough teaching of the six types would have resulted in more accurate or different self-estimations. Future studies could explore how different kinds of presentation and teaching influence the obtained selfestimates.

\section{Implications for Career Counseling and Assessment}

Asking clients to estimate their interest type prior to presenting them their interestprofile is a good way to actively involve clients in the discussion about their assessment results. It also gives the chance to compare the self-concept of the client to the results of the interest inventory and explore the personal meaning of the inventory. At the same time, counselors can rate the self-estimation for its accuracy. In counseling and assessment practice, due to time restrictions, counselors might want to use a simple and short description of the basic interest types to elicit such self-estimations. As our study shows, secondary students can basically be expected to correctly estimate their first interest-type according to such a procedure. Counselors should, however, take into account that not all types are estimated with the same accuracy and especially the Enterprising type is frequently overestimated. While age does not seem to be directly linked to the quality of self-estimation, female students and students with more general scholastic aptitude are slightly better able to accurately estimate 
their type. As our results show, students who fail to correctly name their first interest type can generally be assumed to possess a less developed vocational identity and less total career choice readiness. For these students the interest inventory results should therefore be used with caution. Prior to making any premature decisions on basis of the assessment results, counselors should first try to help these students develop a clearer understanding of their own interests, talents, and values before a final choice can be made.

\section{References}

Assouline, M., \& Meir, E. I. (1987). Meta-analysis of the relationship between congruence and well-being measures. Journal of Vocational Behavior, 31, 319-332.

Bergmann, C. (1993). Differenziertheit der Interessen und berufliche Entwicklung [Differentiation of interests and vocational development]. Zeitschrift für Differentielle und Diagnostische Psychologie, 14, 265-279.

Bergmann, C., \& Eder, F. (2005). Allgemeiner Interessen-Struktur-Test. Revidierte Fassung (AIST-R) [GeneralInterest-Structure-Inventory. Revised Version]. Weinheim: Verlag Beltz.

Brown, S. D., \& Gore, P. A. (1994). An evaluation of interest congruence indices: Distribution characteristics and measurement properties. Journal of Vocational Behavior, 45, 310-327.

Camp, C. C., \& Chartrand, J. M. (1992). A comparison and evaluation of interest congruence indices. Journal of Vocational Behavior, 41, 162-182.

Creed, P. A., \& Patton, W. (2003). Predicting two components of career maturity in school based adolescents. Journal of Career Development, 29, 277-290.

Creed, P. A., Prideaux, L.-A., \& Patton, W. (2005). Antecedents and consequences of career decisional states in adolescence. Journal of Vocational Behavior, 67, 397-412.

Crites, J. O. (1973). Theory and research handbook for the Career Maturity Inventory. Monterey, CA: CTB/McGraw Hill.

Crites, J. O. (1978). Theory and research handbook for the Career Maturity Inventory (2nd ed.). Monterey, CA: CTB/McGraw-Hill.

Eggerth, D. E., \& Andrew, M. E. (2006). Modifying the C Index for Use With Holland Codes of Unequal Length. Journal of Career Assessment, 14, 267-275.

Gottfredson, G. D. (2002a). Interests, aspirations, self-estimates, and the Self-Directed Search. Journal of Career Assessment, 10, 200-208.

Gottfredson, L. S. (2002b). Gottfredson's Theory of circumscription, compromise, and self-creation. In D. Brown \& Associates (Eds.), Career choice and development (4th ed., pp. 85-148). San Francisco, CA: Jossey-Bass.

Hansen, J.-I. C. (2005). Assessment of interests. In S. D. Brown \& R. W. Lent (Eds.), Career Development and Counseling (pp. 281-304). Hoboken, NJ: John Wiley \& Sons.

Healy, C. C., \& Mourton, D. L. (1983). Derivatives of the Self-Directed Search: Potential clinical and evaluative uses. Journal of Vocational Behavior, 23, 318-328. 
Hirschi, A., \& Werlen Lutz, C. (submitted). Berufswahlbereitschaft und Erfolg bei der Lehrstellensuche: Der Einfluss von Planung, Exploration, Entschiedenheit und beruflicher Identität. [Career choice readiness and success in finding an apprenticeship: The influence of planfulness, exploration, decidedness, and vocational identity]. Zeitschrift für Pädagogische Psychologie.

Holland, J. L. (1994). The Self Directed Search. Odessa, FL: Psychological Assessment Resources.

Holland, J. L. (1997). Making vocational choices: A theory of vocational personalities and work environments (3rd ed.). Englewood Cliffs, NJ: Prentice Hall.

Holland, J. L., Daiger, D. C., \& Power, P. G. (1980). My Vocational Situation. Palo Alto, CA: Consulting Psychologists Press.

Jörin, S., Stoll, F., Bergmann, C., \& Eder, D. (2004). Explorix ${ }^{\circledR}$ - das Werkzeug zur Berufswahl und Laufbahnplanung [Explorix - the Tool for Career Choice and Career Planning]. Bern: Hans Huber.

Krumboltz, J. D. (1992). The wisdom of indecision. Journal of Vocational Behavior, 41, 239-244.

McMahon, M., \& Patton, W. (2002). Using qualitative assessment in career counselling. International Journal for Educational and Vocational Guidance, 2, 51-66.

Mitchell, K. E., Levin, A. S., \& Krumboltz, J. D. (1999). Planned happenstance: Constructing unexpected career opportunities. Journal of Counseling and Development, 77, 115-124.

Patton, W., Creed, P. A., \& Muller, J. (2002). Career maturity and well-being as determinants of occupational status of recent school leavers: A brief report of an Australian study. Journal of Adolescent Research, $17,425-435$.

Phillips, S. D. (1997). Toward an expanded definition of adaptive decision making. Career Development Quarterly, 45, 275-287.

Phillips, S. D., \& Blustein, D. L. (1994). Readiness for career choices: Planning, exploring, and deciding. Career Development Quarterly, 43, 63-74.

Reardon, R. C., \& Lenz, J. G. (1999). Holland's theory and career assessment. Journal of Vocational Behavior, $55,102-113$.

Rojewski, J. W. (2005). Occupational aspirations: Constructs, meanings, and application. In S. D. Brown \& R. W. Lent (Eds.), Career development and counseling (pp. 131-154). Hoboken, NJ: Wiley \& Sons Inc.

Savickas, M. L. (2001). Toward a comprehensive theory of career development: dispositions, concerns, and narratives. In F. T. L. Leong \& A. Barak (Eds.), Contemporary models in vocational psychology: A volume in honor of Samuel H Osipow (pp. 295-320). Mahwah, NJ: Lawrence Erlbaum Associates.

Savickas, M. L. (2005). The theory and practice of career construction. In S. D. Brown \& R. W. Lent (Eds.), Career Development and Counseling (pp. 42-70). Hoboken, NJ: Wiley \& Sons Inc.

Savickas, M. L., Briddick, W. C., \& Watkins, C. E. J. (2002). The relation of career maturity to personality type and social adjustment. Journal of Career Assessment, 10, 24-41.

Seifert, K. H. (1983). Berufswahlreife [Career maturity]. Berufsberatung und Berufsbildung, 68, $233-251$.

Seifert, K. H. (1993). Zur prädikativen Validität von Berufswahlreifeinstrumenten [On the predictive validity of career maturity measures]. Zeitschrift für Arbeits- und Organisationspsychologie, 4, 172 - 182.

Seifert, K. H., Bergmann, C., \& Eder, F. (1987). Berufswahlreife und Selbstkonzept-Berufskonzept-Kongruenz als Prädiktor der beruflichen Anpassung und Bewährung während der beruflichen Ausbildung [Career 
maturity and self-concept-vocation-concept congruence as a predictor for vocational adaption and success in vocational education]. Zeitschrift für Arbeits- und Organisationspsychologie, 31, 133-143.

Seifert, K. H., \& Eder, F. (1985). Der Fragebogen zur Laufbahnentwicklung [Questionnaire on Career Development]. Zeitschrift für Differenzielle und Diagnostische Psychologie, 6, 65-77.

Seifert, K. H., \& Eder, F. (1991). Berufswahl und berufliche Bewährung und Anpassung während der beruflichen Ausbildung [Career choice and vocational success and adaption during vocational education]. Zeitschrift für Pädagogische Psychologie, 5, 187 - 200.

Seifert, K. H., \& Stangl, W. (1986). Der Fragebogen Einstellung zur Berufswahl und beruflichen Arbeit [Questionnaire on Attitudes towards Career Choice and Work]. Diagnostica, 32, 153-164.

Silvia, P. J. (2001). Expressed and measured vocational interests: Distinctions and definitions. Journal of Vocational Behavior, 59, 382-393.

Skorikov, V., \& Vondracek, F. W. (1998). Vocational identity development: Its relationship to other identity domains and to overall identity development. Journal of Career Assessment, 6, 13-35.

Super, D. E. (1990). A life-span, life-space approach to career development. In D. Brown \& L. Brooks (Eds.), Career choice and development: Applying contemporary theories to practice (2nd ed., pp. 197-262). San Francisco, CA: Jossey-Bass.

Super, D. E., Thompson, A. S., Lindeman, R. H., Jordaan, J.-P., \& Myers, R. A. (1981). Career Development Inventory. Palo Alto, CA: Consulting Psychologists Press.

Vondracek, F. W., \& Reitzle, M. (1998). The viability of career maturity theory: A developmental-contextual perspective. Career Development Quarterly, 4, 6-15.

Watkins, C. E., Jr., Campbell, V. L., \& Nieberding, R. (1994). The practice of vocational assessment by counseling psychologists. The Counseling Psychologist, 22, 115-128.

Young, G., Tokar, D. M., \& Subich, L. M. (1998). Congruence revisited: Do 11 indices differentially predict job satisfaction and is the relation moderated by person and situation variables? Journal of Vocational Behavior, 52, 208-233.

Young, R. A., \& Collin, A. (2004). Introduction: Constructivism and social constructivism in the career field. Journal of Vocational Behavior, 64, 373-388.

Zener, T. B., \& Schnuelle, L. (1976). Effects of the Self-Directed Search on high school students. Journal of Counseling Psychology, 23, 353-359.

Zytowski, D. G. (1999). How to talk to people about their interest inventory results. In M. L. Savickas \& A. R. Spokane (Eds.), Vocational Interests: Meaning, Measurement, and Counseling Use (pp. 277-293). Palo Alto, CA: Davies-Black Publishing. 
Accuracy of Self-Estimated Interest Type and Career Choice Readiness 23

\section{Table 1}

Correlations (Pearson) between accuracy of self-estimation and measures of career choice readiness and secondary constructs $(N=350)$.

\begin{tabular}{|c|c|c|c|c|c|c|c|c|c|}
\hline$\underline{\mathrm{ASE}}$ & $\underline{V I D}$ & $\underline{C D}$ & $\underline{C P}$ & $\underline{C E}$ & $\underline{T C C}$ & Coher & $\underline{\text { Diff }}$ & Congr $^{3}$ & $\underline{\text { Cons }}$ \\
\hline & & & & & $\underline{R}$ & $\underline{2}$ & & & \\
\hline Difference-index ${ }^{1}$ & $.137^{* *}$ & -.057 & .003 & .040 & -.057 & .027 & $.336^{* * *}$ & $.263^{* * *}$ & .087 \\
\hline Holland-index & $.118^{*}$ & .056 & .029 & .040 & .085 & .119 & $.227^{* * * *}$ & $.364^{* * *}$ & $.186^{* * *}$ \\
\hline Z-S-index & .096 & .027 & -.037 & -.044 & .022 & -.014 & $.389^{* * *}$ & $.270^{* * *}$ & .102 \\
\hline C-index & .050 & -.004 & -.023 & .018 & .015 & .016 & $.230^{* *}$ & $.377^{* * *}$ & $.175^{* * *}$ \\
\hline
\end{tabular}

Note: ASE: Accuracy of Self-Estimation; VID: Vocational Identity; CD: Career Decidedness;

$C P$ : Career Planning; CE: Career Exploration; TCCR: Total Career Choice Readiness; Coher:

Coherence; Diff: Differentiation; Congr: Congruence; Cons: Consistency

${ }^{1}$ Correlations were multiplied by -1 to result in positive correlations for more accuracy.

${ }^{2}$ Coherence could only be calculated for students who named at least three career aspirations $(\mathrm{N}=172)$.

${ }^{3}$ The values for congruence are the respective correlations between the corresponding congruence indices (e.g., both Holland-index), for the Difference-index the mean correlation to all three congruence indices is reported $(\mathrm{SD}=.074)$.

${ }^{*} \mathrm{p} \leq .05 ;{ }^{* *} \mathrm{p} \leq .01 ;{ }^{* * *} \mathrm{p} \leq .001$ 
Accuracy of Self-Estimated Interest Type and Career Choice Readiness 24

\section{Table 2}

Comparison of career choice readiness between accurate and inaccurate first interest-type estimation.

\begin{tabular}{lccccccc}
\hline & \multicolumn{5}{c}{ first type estimated } & & \\
\cline { 2 - 5 } & \multicolumn{2}{c}{ correctly $(\mathrm{N}=169)$} & \multicolumn{2}{c}{ incorrectly $(\mathrm{N}=86)$} & & \\
& $M$ & $S D$ & $M$ & $S D$ & & $d f^{\prime}$ & $t$ \\
$\mathrm{VID}$ & 35.51 & 7.72 & 33.11 & 7.53 & 253 & $2.37^{*}$ \\
$\mathrm{CD}$ & 34.99 & 6.63 & 33.58 & 6.37 & 253 & 1.62 \\
$\mathrm{CP}$ & 69.73 & 13.53 & 68.93 & 13.09 & 251 & 0.45 \\
$\mathrm{CE}$ & 86.64 & 14.29 & 84.24 & 14.46 & 252 & 1.26 \\
TCCR & 3.40 & 0.03 & 3.27 & 0.05 & 251 & $2.01^{*}$ \\
\hline
\end{tabular}

Note: VID: Vocational Identity; $C D$ : Career Decidedness; $C P$ : Career Planning; $C E$ : Career Exploration; TCCR: Total Career Choice Readiness

${ }^{1} d f$ vary because not all students correctly completed all scales.

${ }^{*} \mathrm{p} \leq .05 ;$ (one-tailed) 